\title{
POST-COAGULATION SLUDGE AS AN ADSORBENT OF DYES FROM AQUEOUS SOLUTIONS
}

\author{
OSAD POKOAGULACYJNY JAKO ADSORBENT BARWNIKÓW \\ Z ROZTWORÓW WODNYCH
}

\begin{abstract}
The main source of usable water supply in Poland is surface water. The most frequently used methods of surface water treatment are coagulation and filtration processes. During these processes post-coagulation sludge is generated, which is the main waste produced in water treatment plants. This sludge is characterized by an amorphous structure with a strongly developed specific surface, similar to sewage sludge. Dried and crushed post-coagulation sludge was used in the studies as an adsorbent of two acid dyes: Acid Red 18 (AR 18) and Acid Green 16 (AG 16). The most favourable $\mathrm{pH}$ of process and contact time as well as sorption isotherm were established. For both dyes the most favourable $\mathrm{pH}$ value was equal 2. The tests showed that in the case of AR 18 (180 $\mathrm{min})$ a longer contact time was necessary to reach the equilibrium than for AG 16 (120 min). Moreover, based on the different isotherm two-parameter models, the sorption capacity, type of sorption and energy of sorption were calculated based on linear and non-linear regression. The tests showed that in the case of dye AG 16 monolayer sorption occurred - the analysis showed better fitting the results to Langmuir model. Moreover, for both dyes, physical adsorption took place - it was indicated by the values of parameter $1 / n$ (computed from the Freundlich model).
\end{abstract}

Keywords: water treatment, dye adsorption, waste sorbents, sorption isotherm

\section{Introduction}

The surface water is the main source of supply of usable water. The raw water has to be purified by different kinds of processes before it is fed into the supplying network and to recipients [1]. As a result of treatment processes, waste products are generated such as technological wastewater, usually called backwash water, and sludge. The surface water is mainly treated by coagulation/flocculation and filtration methods $[1,2]$. Therefore, the main waste product, generated in water treatment plants, is post-coagulation sludge. It contains all contaminants removed from raw water during the purifying process. The removal of very small particles of suspension from water, the microorganisms among them, influences the increase of organic content in sludge.

Taking into account the process of compliance of Polish legal provisions with the guidelines and requirements of the European Union, restrictions were introduced to lower

${ }^{1}$ Faculty of Energy and Environmental Engineering, Silesian University of Technology, ul. S. Konarskiego 18, 44-100 Gliwice, Poland, phone +48 3223716 98, fax +48 3223710 47, email: rie4@polsl.pl

*Corresponding author: barbara.pieczykolan@polsl.pl 
the permitted amount of disposed waste (the reduction to $35 \%$ in relation to the amount of waste in 1995) and to prohibit the disposal of waste containing organic matter above $5 \%$.

In addition, the Waste Act obliges waste producers to use technology that minimizes the threat and nuisance to the environment and requires minimization of the amount of waste generated. Moreover, the law also requires the use of waste recovery and only in the absence of such a possibility, it allows its storage [3].

At present, post-coagulation sludge, similarly to sewage sludge, should be subjected to processes enabling their disposal. Sludge disposal is aimed at reducing the volume and mass of sludge, reducing putrescibility and killing pathogenic organisms [3-5].

The flocs of post-coagulation sludge have a well-developed sorption surface. This property also plays an important role in the water purification process and the removal of impurities from it. Then, the process of adsorption of impurities on the surface of flocs of $\mathrm{Fe}(\mathrm{OH})_{3}$ or $\mathrm{Al}(\mathrm{OH})_{3}$ occurs - depending on the kind of coagulant used in the coagulation process.

The paper describes the sorption process of two acid dyes onto dried post-coagulation sludge. Studies included the effect of $\mathrm{pH}$ and sorption time. Moreover the sorption isotherm tests were made and based on the results of those experiments, different parameter of three two-parameter isotherm models were estimated. The estimation was made based on linear and non-linear regression.

\section{Methodology}

\section{Materials and chemicals}

The post-coagulation sludge was used at the studies. The sludge was generated during the treatment of surface water by coagulation-flocculation process when the alum coagulant (as aluminium sulphate $\mathrm{Al}_{2}\left(\mathrm{SO}_{4}\right)_{3} \cdot 18 \mathrm{H}_{2} \mathrm{O}$ ) was used as a reagent. The water treatment plant produces water for consumption and household purposes for the group of cities located in the south of Poland. The raw sludge consisted mainly of the flocky form of aluminium hydroxide, precipitated during volumetric coagulation. The sludge was dewatered in mechanical dewatering process and then dried to the stable mass in the laboratory drier at $105{ }^{\circ} \mathrm{C}$. The sludge prepared in such a procedure was milled and sieved to obtain the particles with a size $<0.49 \mathrm{~mm}$.

Table 1

The characteristics of dyes used in the study [6]

\begin{tabular}{|l|c|c|}
\hline \multicolumn{1}{|c|}{ Parameter } & \\
\hline Structure & $\left(\mathrm{H}_{3} \mathrm{C}\right)_{2} \mathrm{~N}$ & \\
\hline Molecular formula & $\mathrm{C}_{31} \mathrm{H}_{33} \mathrm{~N}_{2} \mathrm{NaO}_{6} \mathrm{~S}_{2}$ & $\mathrm{SO}_{3}$ \\
\hline Molecular weight $[\mathrm{g} / \mathrm{mol}]$ & 616.72 & 16255 \\
\hline C.I. & 44025 & $\mathrm{C}_{20} \mathrm{H}_{11} \mathrm{~N}_{2} \mathrm{Na}_{3} \mathrm{O}_{10} \mathrm{~S}_{3}$ \\
\hline
\end{tabular}

The aqueous solutions of two dyes were used at the tests. One of them was Acid Green 16 (referred as AG 16), triphenylmethane dye with the colour index C.I. 44025 
(Sigma-Aldrich). The second one was azo dye Acid Red 18 (referred as AR 18) of the C.I. number 16255 (Sigma-Aldrich). The characteristic parameters and the structures of these dyes are given in the Table 1.

\section{Adsorption procedure}

The static sorption process was applied during the studies which contained three stages: the effect of initial $\mathrm{pH}$, effect of contact time, and isotherm sorption. At the first stage the experiments were provided in Erlenmeyer flasks of $250 \mathrm{~cm}^{3}$ into which $50 \mathrm{~cm}^{3}$ of dye solution with concentration equalled to $700 \mathrm{mg} / \mathrm{dm}^{3}$ and $0.1 \mathrm{~g}$ of dried post-coagulation sludge were introduced (the concentration of the sludge in the solution was therefore equal to $2 \mathrm{~g} / \mathrm{dm}^{3}$ ). Those sorption parameters were used in the previous studies connected with adsorption process applying the dried excess activated sludge, conducted by Authors [7]. There were applied five different values of $\mathrm{pH}: 2,4,6,8$, and 10 . The $\mathrm{pH}$ values of dye solution were being adjusted by using $10 \% \mathrm{NaOH}$ or $50 \% \mathrm{HCl}$. The flasks were shaken for $120 \mathrm{~min}$. After that process, the samples were centrifuged in order to separate the sludge, and the final concentrations of dyes were measured.

At the second stage of the study, the tests were similar to the first stage, wherein $\mathrm{pH}$ value was stable and the contact time was different in each samples $(t: 5,10,15,30,45,60$, $90,120,240,300 \mathrm{~min})$. The other parameters, i.e. initial dyes concentration, weight of sludge and volume of solution, were identical to the first stage.

At the last stage, the sorption isotherms were determined based on the results obtained from the tests carried out according to the following procedure: initial $\mathrm{pH}$ of dyes solution equalled 2; contact time $t$ obtained from the second stage of the study; the concentration of sludge was $2 \mathrm{~g} / \mathrm{dm}^{3}$; the initial concentration of solution $\left(C_{0}\right)$ in range from 100 to $1600 \mathrm{mg} / \mathrm{dm}^{3}$.

The concentrations of dyes were determined by measuring the absorbance (using the spectrophotometer spectroFlex 6100, WTW) at the appropriate wavelength for each dye and by using the calibration curve. The wavelengths of 506 and $631 \mathrm{~nm}$ were used for measuring of the absorbance of the solutions of AR 18 and AG 16, respectively.

The effect of $\mathrm{pH}$ and effect of contact time were established according to the value of amount of adsorbed dye $q_{e}$ (eq. (1)). Moreover, in the case of the first stage of the study, the graph of dependence of final concentration and $\mathrm{pH}$ value was plotted.

$$
q_{e}=\frac{\left(C_{0}-C_{e}\right)}{m_{s l}}
$$

where: $q_{e}$ - the amount of dye adsorbed at equilibrium $[\mathrm{mg} / \mathrm{g}], C_{0}$ - the initial concentration of dye $\left[\mathrm{mg} / \mathrm{dm}^{3}\right], C_{e}$ - the dye concentration at equilibrium $\left[\mathrm{mg} / \mathrm{dm}^{3}\right], m_{s l}$ - amount of sludge $\left[\mathrm{g} / \mathrm{dm}^{3}\right]$.

At the third stage, the graphs of sorption isotherm $q_{e}=f\left(C_{e}\right)$ were plotted. Moreover, three two-parameter models (Langmuir, Freundlich and Dubinin-Radushkevich) were used in order to calculate the sorption capacity, energy of sorption and to evaluate the type of sorption. The parameters of those models were calculated based on linear and non-linear estimations The linear estimation was made based on the linear regression and the correlation coefficient $R^{2}$ was computed. In the case of the non-linear estimation, "SOLVER $A D D$-IN" in Microsoft's spreadsheet was applied to minimize the value of the residual root mean square error (RMSE). This error is a measure of the accuracy of predictions. As the smaller value of $R M S E$ is calculated, the better fitting of the curve to model is achieved. 
Application of non-linear regression enables the determination of isotherm parameters from the original form of the isotherm equations [8-10]. Therefore nowadays, many researchers use the non-linear estimation for the computing the parameters of isotherm sorption [11-14]. The non-linear forms of those models are described by equations (2)-(5). And the linear forms of isotherm models are given by equations from (6) to (9). The function of error is given by eq. (11).

Non-linear forms of isotherm models:

Freundlich:

$$
q_{e}=K_{F} \cdot C_{e}^{1 / n}
$$

Langmuir:

$$
q_{e}=\frac{C_{e} \cdot K_{L} \cdot q_{m}}{1+K_{L} \cdot q_{m}}
$$

Dubinin-Radushkevich:

$$
\begin{gathered}
q_{e}=Q_{s} \cdot \exp \left(-K_{D R} \cdot \varepsilon^{2}\right) \\
\varepsilon=\mathrm{R} T \cdot \ln \left(1+\frac{1}{C_{e}}\right)
\end{gathered}
$$

Linear forms of isotherm models:

Freundlich:

$$
\log q_{e}=\log K_{F} \cdot \frac{1}{n} \log C_{e}
$$

Langmuir:

$$
\begin{gathered}
\frac{C_{e}}{q_{e}}=\frac{C_{e}}{q_{m}}+\frac{1}{K_{L} \cdot q_{m}} \\
\frac{1}{q_{e}}=\frac{1}{K_{L} \cdot q_{m}} \cdot \frac{1}{C_{e}}+\frac{1}{q_{m}}
\end{gathered}
$$

Dubinin-Radushkevich:

$$
\begin{gathered}
\ln q_{e}=\ln Q_{s}-K_{D R} \cdot \varepsilon^{2} \\
E=\frac{1}{\sqrt{2 \cdot K_{D R}}} \\
R M S E=\sqrt{\frac{\sum_{i=1}^{n}\left(q_{e c a l}-q_{\text {e exp }}\right)_{i}^{2}}{n-2}}
\end{gathered}
$$

where: $q_{e}$ - the amount of dye adsorbed at equilibrium $[\mathrm{mg} / \mathrm{g}], q_{e}$ cal - theoretical concentration of adsorbate on the adsorbent, which have been calculated from one of the isotherm models [mg/g], $q_{e \text { exp }}$ - the experimentally measured adsorbed solid phase concentration of the adsorbate adsorbed on the adsorbent $[\mathrm{mg} / \mathrm{g}], C_{e}$ - the dye concentration at equilibrium $\left[\mathrm{mg} / \mathrm{dm}^{3}\right], m_{s l}$ - amount of sludge $\left[\mathrm{g} / \mathrm{dm}^{3}\right], K_{L}$ - Langmuir constant related to the free energy of adsorption $\left[\mathrm{dm}^{3} / \mathrm{mg}\right], q_{m}$ - maximum adsorption capacity in Langmuir model $[\mathrm{mg} / \mathrm{g}], n$ - Freundlich equation exponents [-], $K_{F}$ - Freundlich constant indicative of the relative adsorption capacity of the adsorbent $\left[\mathrm{mg}^{(1-1 / \mathrm{n})} \mathrm{dm}^{3(1 / \mathrm{n})} / \mathrm{g}\right], Q_{s}$ - theoretical 
monolayer saturation capacity in Dubinin-Radushkevich model [mg/g], $K_{D R}$ - Dubinin-Radushkevich model constant $\left[\mathrm{mol}^{2} / \mathrm{kJ}^{2}\right], E$ - mean energy of sorption [kJ/mol], $\varepsilon$ - Polanyi potential, R - gas constant $8.314 \mathrm{~J} / \mathrm{mol} \cdot \mathrm{K}, T$ - the absolute temperature $[\mathrm{K}], R M S E$ - root mean square error [-].

\section{Results and discussion}

\section{Effect of pH}

At the first stage of the study, the effect of initial $\mathrm{pH}$ value was evaluated. It was observed that only at $\mathrm{pH} 2$ the sorption process occurred (Table 2). The dye concentrations after process were 581.9 and $643.0 \mathrm{mg} / \mathrm{dm}^{3}$ for AR 18 and AG 16 respectively. The amount of adsorbed dye reached the values of 59.1 and $8.1 \mathrm{mg} / \mathrm{g}$ for AR 18 and AG 16 respectively. When the value of $\mathrm{pH}$ was higher than 2 , the final concentration of dye was equal to initial value and the adsorbed amount of dye was 0 . Generally, dyes can be divided into three groups: anionic, cationic and non-ionic. Anionic dyes include direct, acid, and reactive dyes. Dyes used in the study belong to the acid group and they are anionic dyes [15]. They are therefore characterized by a negative charge. The obtained test results coincide with the results of the influence of $\mathrm{pH}$ on the effectiveness of adsorption of acid dyes carried out by many researchers. Similar relations, for example, were noted in the research connected with Acid Red 18 adsorption by using modified activated carbons (by organic acid ammoniums activation) [16] and modified granular anaerobic activated sludge [17]. In both cases, the most effective $\mathrm{pH}$ value was equal to 2 . The obtained results are related to the fact that the $\mathrm{pH}$ value of a given medium affects the electrostatic charge of the surface of adsorbent. At low $\mathrm{pH}$ value, the charge of sorbent surface is positive (as a result of protonation process caused by the presence of large amount of hydrogen ions that cover the surface of the adsorbent). Only in those conditions, can the adsorption process between an anionic dye and the sorbent occur. Although the solution of $\mathrm{pH} 4$ also has the acidic character, it is possible that the amount of hydrogen ions in the solution is insufficient to effectively protonate the sorbent surface and change the surface charge to a positive one. In contrast, when the $\mathrm{pH}$ is high, the positive charge at the solution decreases and the surface of the adsorbent begins to obtain a negative charge [15]. Therefore anionic dyes and negatively charged adsorbent surface will repel each other.

The changes of dye concentration and $q_{e}$ in dependence of initial $\mathrm{pH}$ of dye solution

Table 2

\begin{tabular}{|c|c|c|c|c|}
\hline \multirow{2}{*}{$\mathbf{p H}[-]$} & \multicolumn{2}{|c|}{ AR 18 } & \multicolumn{2}{c|}{ AG 16 } \\
\cline { 2 - 5 } & $\begin{array}{c}\text { Concentration } \\
{\left[\mathbf{m g} / \mathbf{d m}^{3}\right]}\end{array}$ & $\boldsymbol{q}_{e}[\mathbf{m g} / \mathbf{g}]$ & $\begin{array}{c}\text { Concentration } \\
{\left[\mathbf{m g}_{\mathbf{d}} \mathbf{d m}^{3}\right]}\end{array}$ & $\boldsymbol{q}_{\boldsymbol{e}}[\mathbf{m g} / \mathbf{g}]$ \\
\hline 2 & 581.9 & 59,1 & 643.0 & 8.1 \\
\hline 4 & 700.0 & 0.0 & 700.0 & 0.0 \\
\hline 6 & 700.0 & 0.0 & 700.0 & 0.0 \\
\hline 8 & 700.0 & 0.0 & 700.0 & 0.0 \\
\hline 10 & 700.0 & 0.0 & 700.0 & 0.0 \\
\hline
\end{tabular}

\section{Effect of contact time}

The results of that stage of the tests have shown that in the case of AR 18 sorption proceeded the fastest between 10 and $180 \mathrm{~min}$ (Fig. 1). The amount of adsorbed dye increased from 0 to $70.0 \mathrm{mg} / \mathrm{g}$. Prolongation the contact time to above $180 \mathrm{~min}$ did not 
improve the process efficiency and the $q_{e}$ had almost a stable value. In the case of AG 16 the highest growth of adsorbed amount of dye was observed between $15^{\text {th }}$ and $120^{\text {th }}$ min of the process. The value of $q_{e}$ increased from 0 to $26.2 \mathrm{mg} / \mathrm{g}$. The application of longer contact times only slightly improved the efficiency of the process - the $q_{e}$ increased to $30.3 \mathrm{mg} / \mathrm{g}$ at $300^{\text {th }} \mathrm{min}$. Therefore the time of $120 \mathrm{~min}$ was selected as the most favourable in the third stage of study for that dye. In the case of AR 18 as the most favourable contact time $t=180$ min was chosen.

In the case of both dyes, it can be observed that the increase of the amount of adsorbed dyes proceeded in two different stages. In the first period, the increase in the amount of adsorbed dyes molecules proceeded faster, than in the second period when the increase in the number of adsorbed dyes was reduced. This may be due to the fact that in the initial period, where there was an excess of active sites on the adsorbent surface versus to the dyes particles that were being removed from the solution, the process proceeded fast. In the second period however, as the active sites were being covered by dyes molecules, the adsorption rate was reduced (longer time is needed for the molecule to reach free active site during contact with the adsorbent surface).

a)

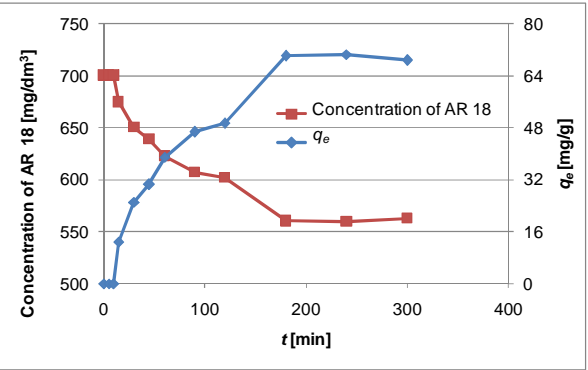

b)

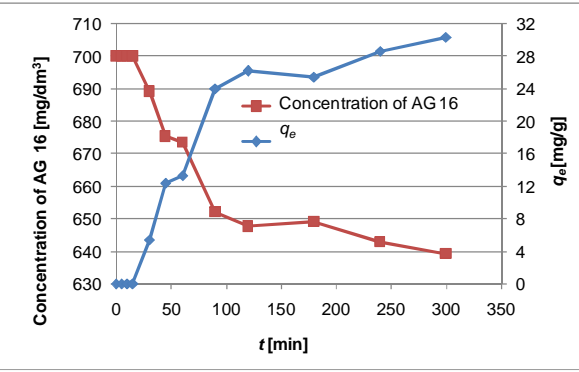

Fig. 1. Effect of contact time on sorption efficiency: a) AR 18, b) AG 16

\section{Sorption isotherm}

Based on the results of that stage of the study, the graphs of sorption isotherm $\left(q_{e}=f\left(C_{e}\right)\right)$ for both dyes were plotted. They are showed at Figures $2 \mathrm{a}$ and $2 \mathrm{~b}$.

a)

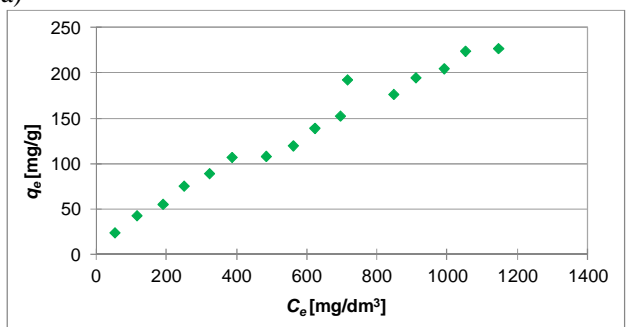

b)

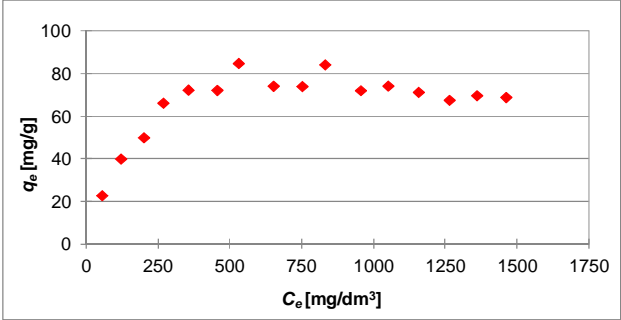

Fig. 2. Sorption isotherm for dye: a) AG 16, b) AR 18 
Much higher values of adsorbed amount of dye $q_{e}$ were obtained in the case of dye AG 16 than in the case of AR 18. Moreover, there was a great difference between the shape of curve of sorption isotherm for both dyes. In the case of the green dye the shape suggests that multilayer sorption occurred. However, for the red dye the shape is quite different, which indicates that monolayer sorption took place. For AR 18 on the graph the plateau was observed when the equilibrium concentration of dye was higher than $400 \mathrm{mg} / \mathrm{dm}^{3}$.

\section{Results of linear regression}

Freundlich isotherm

The Freundlich model is an empirical model that can be used for describing the non-ideal sorption process on heterogeneous surfaces. Moreover, it assumes that energies of adsorption sites are not equivalent, therefore the multilayer sorption is possible [18, 19].

Based on the curve presenting the linear form of Freundlich isotherm model, the parameters $K_{F}$ and $n$ were calculated. These constants are incorporating all factors that affect the process of adsorption, i.e. adsorption capacity and intensity [20]. They also affect the adsorption isotherm. The slope $1 / n$ is a measure of surface heterogeneity: if $1 / n=1$ the adsorption is linear; if $1 / n<1$ then the physical sorption occurs; if $1 / n>1$ it is a chemical sorption [21]. Moreover, the values of $n$ ranging between 1 and 10 represent favourable adsorption [19]. It was observed that for both dyes, the parameter $n$ was lower than 10 and greater than 1, therefore it may be concluded that this model is favourable [19]. The results of the studies showed that higher value of correlation coefficient $R^{2}$ was obtained for green dye (AG 16) then for red one (AR 18). It was equal to 0.9882 and 0.6758 for AG 16 and AR 18 respectively (Fig. 3, Table 3).

a)

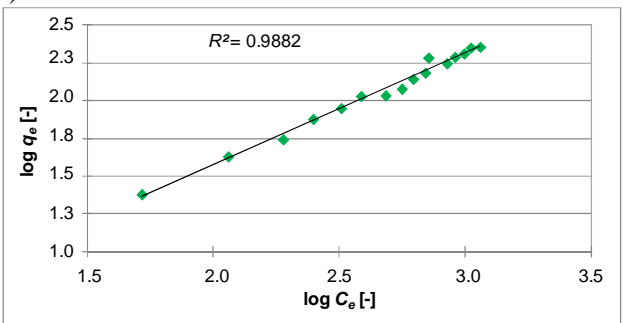

b)

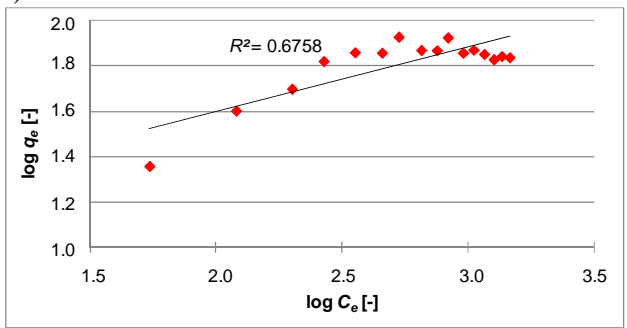

Fig. 3. Linear form of Freundlich isotherm model for: a) AG 16 and b) AR 18

Langmuir isotherm

This model assumes that the monolayer adsorption occurs. This means that if a molecule of adsorbate occupies a site, no further adsorption can occur at that site [19].

In order to calculate the Langmuir parameters, two different equations of linear form of that model were used. The values of correlation coefficient of both linear forms were established. Afterwards, the model parameters were calculated based on that linear form for which $R^{2}$ achieved higher value. In the case of AR 18 higher value of $R^{2}$ was obtained for the first linear equation form of that isotherm model (expressed by eq. (7)) and it was 0.9798 (Fig. 4b, Table 3), while for AG 16 the higher $R^{2}$ was achieved in the case of second linear form described by eq. (8) and its value was 0.9798 (Fig. 5a, Table 3). Based on those 
data, the $q_{m}$ and $K_{L}$ were calculated. It was observed that much larger amount of adsorbed dye by waste sorbent was for dye AG $16\left(q_{m}=256.4 \mathrm{mg} / \mathrm{g}\right)$ in comparison with AR 18 $\left(q_{m}=73.5 \mathrm{mg} / \mathrm{g}\right)-$ Table 3 .

a)

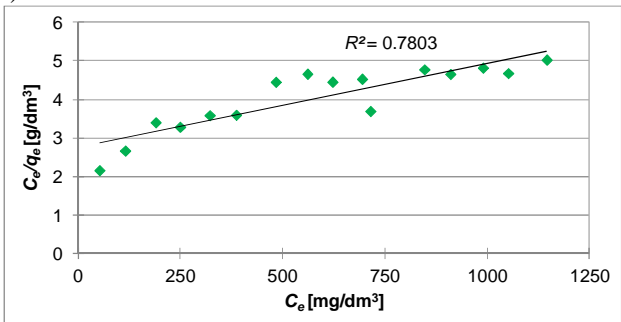

b)

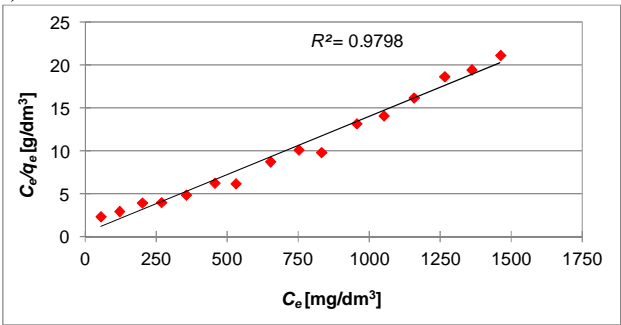

Fig. 4. The first linear form of Langmuir isotherm model according to eq. (7) for: a) AG 16 and b) AR 18

a)

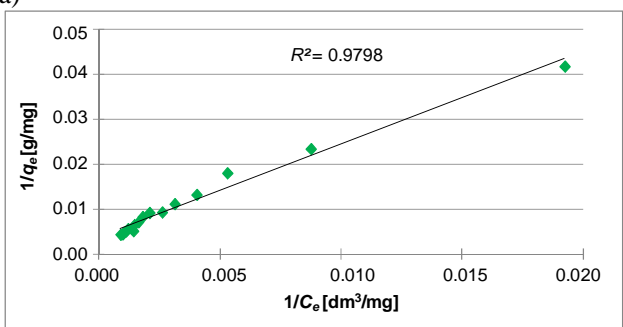

b)

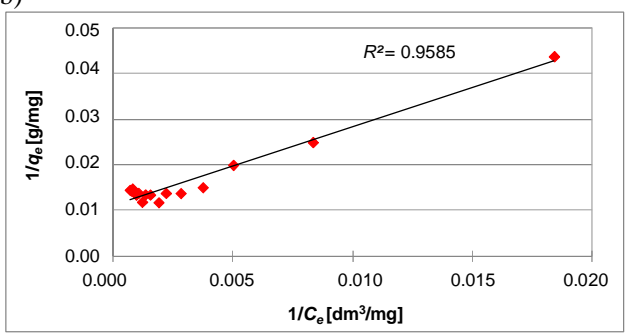

Fig. 5. The second linear form of Langmuir isotherm model according to eq. (8) for: a) AG 16 and b) AR 18

\section{Dubinin-Radushkevich isotherm}

The linear form of Dubinin-Radushkevich isotherm model was shown in Figure 6. Based on the slope and intercept obtained from that curve, the parameters $K_{D R}$ and $Q_{s}$ were calculated. It was observed that higher value of sorption capacity occurred in the case of dye AG 16 in comparison with AR 18. The value of $Q_{s}$ for AG 16 was almost two times higher $(135.8 \mathrm{mg} / \mathrm{g})$ than for AR $18(71.2 \mathrm{mg} / \mathrm{g})$ - Table 3. Moreover, based on the $K_{D R}$ parameter the mean energy of sorption $E$ was calculated according to equation (10). Its value is useful in order to estimate the type of sorption process - whether it is chemical or physical $[22,23]$.The chemical sorption takes place when the value of energy of sorption is higher than $16 \mathrm{~kJ} / \mathrm{mol}$. The physical adsorption takes place, when the value of this energy is lower than $8 \mathrm{~kJ} / \mathrm{mol}$. However, if the value of $E$ is in range $8-16 \mathrm{~kJ} / \mathrm{mol}$, the ion exchange occurs [24-26]. At the study the values of mean energy of sorption were smaller than $8 \mathrm{~kJ} / \mathrm{mol}$ for both dyes (Table 3), therefore it may be concluded that physical sorption occurred. However, due to the very low degree of matching of test results to the Dubinin-Radushkevich model (low $R^{2}$ value), the obtained mean energy values may be subject to a significant error. Therefore, it is not possible to determine the type of adsorption (whether it is physical or chemical) on the basis of these energy values. Due to that fact the authors intend to analyze the results of the experiments using, for example, Temkin isotherm model. According to this model the determination of heat of sorption 
process is possible, (this parameter also determine the type of the process - whether it is physical or chemical).

a)

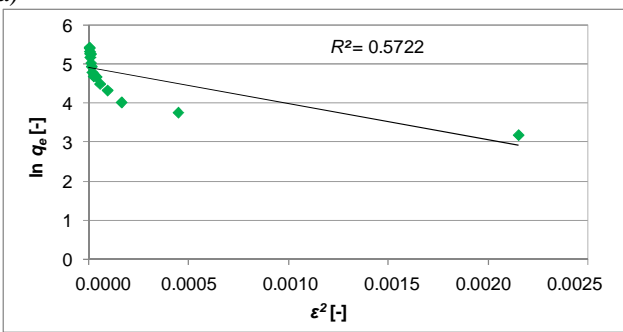

b)

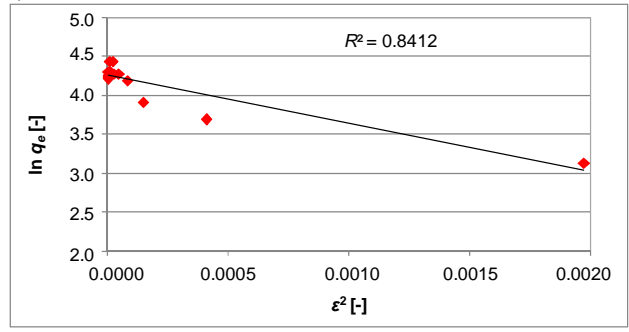

Fig. 6. Linear form of Dubinin-Radushkevich isotherm model for: a) AG 16 and b) AR 18

Parameters of isotherm models for dye AR 18 and AG 16

\begin{tabular}{|c|c|c|c|c|c|}
\hline \multirow[t]{2}{*}{ Isotherm model } & \multirow[t]{2}{*}{ Dye } & \multicolumn{2}{|c|}{ Linear regression } & \multicolumn{2}{|c|}{ Non-linear regression } \\
\hline & & Parameter & Value & Parameter & Value \\
\hline \multirow[t]{6}{*}{ Freundlich } & \multirow[t]{3}{*}{ AR 18} & $K_{F}\left[\mathrm{mg}^{(1-1 / \mathrm{n})} \mathrm{dm}^{3(1 / \mathrm{n})} / \mathrm{g}\right]$ & 10.60 & $K_{F}\left[\mathrm{mg}^{(1-1 / \mathrm{n})} \mathrm{dm}^{3(1 / \mathrm{n})} / \mathrm{g}\right]$ & 19.65 \\
\hline & & $1 / n[-]$ & 0.287 & $1 / n[-]$ & 0.193 \\
\hline & & $R^{2}[-]$ & 0.6758 & $R M S E[-]$ & 10.954 \\
\hline & \multirow[t]{3}{*}{ AG 16} & $K_{F}\left[\mathrm{mg}^{(1-1 / \mathrm{n})} \mathrm{dm}^{3(1 / \mathrm{n})} / \mathrm{g}\right]$ & 1.25 & $K_{F}\left[\mathrm{mg}^{(1-1 / \mathrm{n})} \mathrm{dm}^{3(1 / \mathrm{n})} / \mathrm{g}\right]$ & 1.06 \\
\hline & & $1 / n[-]$ & 0.738 & $1 / n[-]$ & 0.766 \\
\hline & & $R^{2}[-]$ & 0.9882 & $R M S E[-]$ & 10.624 \\
\hline \multirow[t]{6}{*}{ Langmuir } & \multirow[t]{3}{*}{ AR 18} & $q_{m}[\mathrm{mg} / \mathrm{g}]$ & 73.5 & $q_{m}[\mathrm{mg} / \mathrm{g}]$ & 82.2 \\
\hline & & $K_{L}\left[\mathrm{dm}^{3} / \mathrm{mg}\right]$ & 0.0308 & $K_{L}\left[\mathrm{dm}^{3} / \mathrm{mg}\right]$ & 0.0105 \\
\hline & & $R^{2}[-]$ & 0.9798 & $R M S E[-]$ & 7.560 \\
\hline & \multirow[t]{3}{*}{ AG 16} & $q_{m}[\mathrm{mg} / \mathrm{g}]$ & 256.41 & $q_{m}[\mathrm{mg} / \mathrm{g}]$ & 646.1 \\
\hline & & $K_{L}\left[\mathrm{dm}^{3} / \mathrm{mg}\right]$ & 0.0019 & $K_{L}\left[\mathrm{dm}^{3} / \mathrm{mg}\right]$ & 0.0005 \\
\hline & & $R^{2}[-]$ & 0.9798 & $R M S E[-]$ & 11.365 \\
\hline \multirow{8}{*}{$\begin{array}{c}\text { Dubinin- } \\
\text { Radushkevich }\end{array}$} & \multirow[t]{4}{*}{ AR 18} & $Q_{s}[\mathrm{mg} / \mathrm{g}]$ & 71.2 & $Q_{s}[\mathrm{mg} / \mathrm{g}]$ & 73.5 \\
\hline & & $K_{D R}\left[\mathrm{~mol}^{2} / \mathrm{kJ}^{2}\right]$ & 617 & $K_{D R}\left[\mathrm{~mol}^{2} / \mathrm{kJ}^{2}\right]$ & 1038 \\
\hline & & $R^{2}[-]$ & 0.8412 & $R M S E[-]$ & 7.538 \\
\hline & & $E[\mathrm{~kJ} / \mathrm{mol}]$ & 0.0284 & $E[\mathrm{~kJ} / \mathrm{mol}]$ & 0.0220 \\
\hline & \multirow[t]{4}{*}{ AG 16} & $Q_{s}[\mathrm{mg} / \mathrm{g}]$ & 135.8213 & $Q_{s}[\mathrm{mg} / \mathrm{g}]$ & 212.4 \\
\hline & & $K_{D R}\left[\mathrm{~mol}^{2} / \mathrm{kJ}^{2}\right]$ & 917 & $K_{D R}\left[\mathrm{~mol}^{2} / \mathrm{kJ}^{2}\right]$ & 16128 \\
\hline & & $R^{2}[-]$ & 0.5722 & $R M S E[-]$ & 27.907 \\
\hline & & $E[\mathrm{~kJ} / \mathrm{mol}]$ & 0.0233 & $E[\mathrm{~kJ} / \mathrm{mol}]$ & 0.0056 \\
\hline
\end{tabular}

\section{Results of non-linear regression}

Based on the results of the experiments, the parameters of three isotherm models were calculated using the non-linear estimation. The estimation showed that in the case of dye AR 18, a lower RMSE value was obtained for Langmuir model (7.560) than for Freundlich (10.624). In contrast, for the AG 16 dye, the inverse relationship was obtained: a lower value of RMSE was obtained for Freundlich (10.954) than Langmuir (11.365) model. These results indicate that AG 16 dye adsorption is better matched with the Langmuir model than that of AR 18. It also suggests that in the case of AG 16, monolayer sorption occurred.

The sorption capacity $q_{m}$ was also calculated based on the Langmuir model. The results of the estimation showed that a much higher value was obtained for the dye AG 16 
$\left(q_{m}=646.1 \mathrm{mg} / \mathrm{g}\right)$ than AR $18\left(q_{m}=82.2 \mathrm{mg} / \mathrm{g}\right)$. A similar relationship was obtained when $Q_{s}$ was calculated based on the Dubinin-Radushkevich model. Also in this case the sorption capacity was significantly higher for the dye AG $16\left(Q_{s}=73.5 \mathrm{mg} / \mathrm{g}\right)$ than for AR 18 $\left(Q_{s}=212.4 \mathrm{mg} / \mathrm{g}\right)$ - Table 3 .

The value of the mean energy of sorption $E$, calculated according to Dubinin-Radushkevich for both dyes, indicates the occurrence of the physical adsorption process. Moreover, the calculated values of $1 / n$ (based on Freundlich model), which were below 1 for both dyes, also indicated that the physical adsorption occurred.

The investigations of the adsorption process for the removal of different types of dyes from aqueous solutions were carried out by many researchers and with applying many different adsorbents. Swan and Zaini [27], for example, made in their article a list of different types of adsorbents used by different researchers to remove two dyes: malachite Green and Congo Red. They reported that such sorbent as bio-based magnetic activated carbon, reduced graphene oxide, fibrous cellulose sulphate, zeolitic imidazolate, shrimp shell powder and many other sorbents were used for that purpose. There are also many research connected with acid dye removal using adsorption process. In particular, the AR 18 dye is broadly studied. In this case, many different types of sorbents have already been used, such as natural and surfactant modified zeolites [28], chitosan [29], modified clinoptilolite zeolite [30] and dithiocarbamate-modified starch [31]. In the case of surfactant modified zeolite, the sorption capacity $q_{m}$ was equal to $20.42 \mathrm{mg} / \mathrm{g}$ and for natural zeolite it was only $1.17 \mathrm{mg} / \mathrm{g}$ [28]. In the case of application of chitosan, the results showed that this sorbent was characterized by sorption capacity in the range from 31.8 to $218.3 \mathrm{mg} / \mathrm{g}$, depending on the temperature and the type of chitosan used [29]. When the modify clinoptilolite zeolite was used, the sorption capacity was $11 \mathrm{mg} / \mathrm{g}$ [30]. Also, the authors of this article carried out the adsorption process of AR 18 and AG 16 using a waste sorbent (dried excess activated sludge) [7]. The research showed that the sorption capacity of the dried excess sludge (calculated on the basis of linear regression) in relation to these two dyes was higher and equal to 109.89 and $434.78 \mathrm{mg} / \mathrm{g}$ for AR 18 and AG 16, respectively.

\section{Conclusions}

The studies were conducted in order to verify if dried post-coagulation sludge may be used as waste sorbent for dyes Acid Red 18 and Acid Green 16. The tests consisted of three stages: estimation of $\mathrm{pH}$ of sorption process; estimation the favourable contact time, and determination of isotherm sorption parameters. Based on the results of the studies the following can be concluded:

1. The most favourable $\mathrm{pH}$ of the sorption process for both dyes is equal to 2 .

2. In the case of dye AR 18 the sorption process proceeded slower than in the case of AG 16. The most favourable contact time was equal to $180 \mathrm{~min}$ and $120 \mathrm{~min}$ for AR 18 and AG 16 respectively.

3. The shape of sorption isotherm graph indicates that monolayer and multilayer sorptions took place in the case of AR 18 and AG 16, respectively.

4. In the case of AR 18 the highest value of correlation coefficient $R^{2}$ and the smallest value of RMSE were obtained for Langmuir isotherm model - this fact also indicated the monolayer sorption occurrence. 
5. In the case of AG 16 the highest value of $R^{2}$ and the smallest value of RMSE were achieved for Freundlich isotherm model, which indicated that multilayer sorption occurred.

6. In the case of both dyes, physical sorption took place - the values of $1 / n$ (Freundlich constant), calculated by both linear and non-linear estimations, were lower than 1 .

7. The higher value of sorption capacity was observed for AG 16 in comparison with AR 18 , which was indicated by the values of $q_{m}$ (calculated from Langmuir model) calculated with both types of estimation methods, linear and non-linear. It may be connected with the fact that in the case of AG 16 multilayer sorption occurred and for AR 18 monolayer one took place.

\section{Acknowledgments}

This work was supported by Ministry of Science and Higher Education Republic of Poland within statutory funds.

\section{References}

[1] Davis Mackenzie L. Water and Wastewater Engineering. Design Principles and Practice. New York:Professional Edition; 2010. ISBN 9780071713849.

[2] Teh CY, Wu TY. Chem Eng Trans. 2014;39:1603-1608. DOI: 10.3303/CET1439268.

[3] Kacprzak M, Neczaj E, Fijałkowski K, Grobelak A, Grosser A, Worwag M, et al. Environ Res. 2017;156:39-46. DOI: 10.1016/j.envres.2017.03.010.

[4] Council Directive 1999/31/EC of 26 April 1999 on the landfill of waste. https://eur-lex.europa.eu/ legal-content/EN/TXT/PDF/?uri=CELEX:31999L0031\&from=EN.

[5] Neyens E, Baeyens J, Dewil R, De Heyder B. J Hazard Mater. 2004;106(2-3):83-92. DOI: 10.1016/j.jhazmat.2003.11.014.

[6] https://pubchem.ncbi.nlm.nih.gov/compound.

[7] Pieczykolan B, Płonka I. Proc ECOpole. 2018;12(1):219-227. DOI: 10.2429/proc.2018.12(1)022.

[8] Prasad AL, Santhi T, Manonmani S. Arabian J Chem. 2015;8:343-354. DOI: 10.1016/j.arabjc.2011.01.020.

[9] Kumar KV, Sivanesan S. J Hazard Mater. 2005;126:198-201. DOI: 10.1016/j.jhazmat.2005.06.007.

[10] Tsai SC, Juan KW. J Radioanal Nucl Chem. 2000;243:741-746. DOI: 10.1023/A:1010694910170.

[11] Hamdaoui O. Desalination. 2011;271:279-286. DOI: 10.1016/j.desal.2010.12.043.

[12] Dragan ES, Loghin DFA. Chem Eng J. 2013;234:211-222. DOI: 10.1016/j.cej.2013.08.081.

[13] Slimani R, El Ouahabi I, Abidi F, El Haddad M, Regti A, Laamari MR, et al. J Taiwan Inst Chem Eng. 2014;45:1578-1587. DOI: 10.1016/j.jtice.2013.10.009.

[14] Yagub MT, Sen TK, Afroze S, Ang HM. Adv Colloid Interface Sci. 2014;209:172-184. DOI: 10.1016/j.cis.2014.04.002.

[15] Salleh MAM, Mahmoud DK, Abdul Karim WAW, Idris A. Desalination. 2011;280:1-13. DOI: 10.1016/j.desal.2011.07.019.

[16] Wang L, Chen Z, Wen H, Cai Z, He C, Wang Z, et al. Powder Technol. 2018;323:230-237. DOI: 10.1016/j.powtec.2017.10.021.

[17] Sun XF, Wang SG, Cheng W, Fan M, Tian BH, Gao BY, et al. J Hazard Mater. 2011;189: 27-33. DOI: 10.1016/j.jhazmat.2011.01.028.

[18] Hamidpour M, Kalbasi M, Afyuni M, Shariatmadari H, Furrer G. Environ Earth Sci. 2011;62:559-568. DOI: 10.1007/s12665-010-0547-x.

[19] Li X, Wang GZ, Li WG, Wang P, Su CY. J Cent South Univ. 2015; 22:103-113. DOI: $10.1007 / \mathrm{s} 11771-015-2500-3$

[20] Jain M, Garg VK, Kadirvelu K. J Hazard Mater. 2009;162:365-372. DOI: 10.1016/j.jhazmat.2008.05.048.

[21] Bang SY, Kim JH. Biotechnol Bioproc E. 2017;22:620-630. DOI: 10.1007/s12257-017-0247-4.

[22] Low SK, Tan MC. J Environ Chem Eng. 2018;6:3502-3509. DOI: 10.1016/j.jece.2018.05.013.

[23] Dada AO, Olalekan AP, Olatunya AM, Dada O. IOSR J Appl Chem. 2012;3:38-45. DOI: $10.9790 / 5736-0313845$.

[24] Amrhar O, Nassali H, Elyoubi MS. J Chem Pharm Res. 2015;7(9):892-903. http://www.jocpr.com/archive/jocpr-volume-7-issue-9-year-2015.html. 
[25] Moradia M, Karimzadeh R, Moosavi ES. Fuel. 2018;217:467-477. DOI: 10.1016/j.fuel.2017.12.095.

[26] Oguz E. Colloids and Surfaces A: Physicochem Eng Aspects. 2007;295:258-263. DOI: 10.1016/j.colsurfa.2006.09.009.

[27] Swan B, Zaini MAA. Ecol Chem Eng S. 2019;26(1):119-132. DOI: 10.1515/eces-2019-0009.

[28] Mirzaei N, Hadi M, Gholami M, Fard RF, Aminabad MS. J Taiwan Inst Chem Eng. 2016;59:186-194. DOI: 10.1016/j.jtice.2015.07.010.

[29] Gao Q, Zhu H, Wen-Jun L, Wang S, Zhou CG. Microporous Mesoporous Mater. 2014;193:15-26. DOI: 10.1016/j.micromeso.2014.02.025.

[30] Mirzaei N, Ghaffari HR, Sharafi K, Velayati A, Hoseindoost G, Adabi S, et al. J Environ Chem Eng. 2017;5:3151-3160. DOI: 10.1016/j.jece.2017.06.008.

[31] Cheng R, Xiang B, Li Y, Zhang M. J Hazard Mater. 2011;188:254-260. DOI: 10.1016/j.jhazmat.2011.01.104. 